\title{
From points to Poles: extrapolating point measurements of sea-ice mass balance
}

\author{
Don PEROVICH, Jacqueline A. RICHTER-MENGE \\ US Army Cold Regions Research and Engineering Laboratory, 72 Lyme Road, Hanover, NH 03755-1290, USA \\ E-mail: donald.k.perovich@erdc.usace.army.mil
}

\begin{abstract}
The amount of ice growth and ablation are key measures of the thermodynamic state of the ice cover. While ice extent and even ice thickness can be determined using remote-sensing techniques, this is not the case for the mass balance. Mass-balance measurements require an ability to attribute the change, establishing whether a change in the thickness of the ice cover occurs at the top or bottom surface and whether it is a result of growth or ablation. We have developed and implemented a tool that can be used to measure thermodynamic changes in sea-ice mass balance at individual locations: the ice mass-balance buoy (IMB). The primary limitation of the IMB is that it provides a point measurement of the ice mass balance, defined by a particular combination of snow and ice conditions. Determining if, and how, such point measurements can be extrapolated is critical to understanding the large-scale mass balance of the sea-ice cover. We explore the potential for extrapolation using mass-balance observations from the Surface Heat Budget of the Arctic (SHEBA) field experiment. During SHEBA, mass-balance measurements were made at over 100 sites covering a $100 \mathrm{~km}^{2}$ area. Results indicate that individual point measurements can provide reasonable estimates for undeformed and unponded multi-year ice, which represented more than two-thirds of the ice cover at SHEBA and is the dominant ice type in the perennial pack. A key is carefully selecting a representative location for the instrument package. The contribution of these point measurements can be amplified by integrating them with other tools designed to measure ice thickness and assimilating these combined data into sea-ice models.
\end{abstract}

\section{INTRODUCTION}

Recent observations are consistent in their indication that the Arctic sea-ice cover is undergoing tremendous change. Satellite-derived estimates show a significant negative trend in areal extent. Between 1978 and 1999, the maximum ice extent in the Northern Hemisphere experienced a net reduction at an average rate of $3 \%$ decade $^{-1}$ (e.g. Parkinson and others, 1999; Parkinson and Cavalieri, 2002). A report by Comiso (2002) indicates an even more rapid reduction in the extent of the perennial sea-ice cover, of $9 \%$ decade $^{-1}$ over the same period. The summer of 2005 marked a new record in the minimum summer ice extent (personal communication from J.C. Stroeve, 2005). Perhaps even more significant is the observation that the summers of 2002-05 have marked an unprecedented series of extreme ice-extent minima (Stroeve and others, 2005). Ice-thickness data, derived from submarine-based upward-looking sonar, also suggest a net thinning of the perennial sea-ice cover since 1958 (Rothrock and others, 1999; Wadhams and Davis, 2000; Tucker and others, 2001). Satellite-derived observations of the onset and end of surface melt indicate an increase in the variability of the length of the melt season, with a higher maximum length (Belchansky and others, 2004). Over the period 1979-87, the average length of the melt season in the perennial ice zone varied from 60 to 70 days. Between 1988 and 2001, the range increased to 55-95 days. In both cases, the length of the melt season decreased with an increase in latitude.

Large-scale general circulation models indicate that Arctic sea ice may be a sensitive indicator of climate change. However, the details of the complex atmosphereice-ocean interaction are not well understood. This combination of potential importance and limited understanding is a primary motivation for numerous, recent investigations and the development of new technologies. An area of particular interest is the mass balance of the ice cover. The mass balance of the ice cover is a key climate-change indicator, since it is an integrator of both the surface heat budget and the ocean heat flux. If there is net warming over time, then there will be thinning of the ice. Conversely, a net cooling leads to thicker ice. The mass balance of the sea-ice cover is a result of ice-dynamic and thermodynamics processes. On the basin scale, these processes act together to influence the thickness distribution of the ice cover.

We have developed and implemented a tool that can be used to measure thermodynamic changes in sea-ice mass balance at individual locations: the ice mass-balance buoy (IMB; Richter-Menge and others, 2006). The IMB is an autonomous, drifting buoy equipped with a datalogger, satellite transmitter and batteries that permit the remote collection and transmission of data for up to 3 years. The instrumentation on the buoys includes a barometer, acoustic rangefinders placed above the ice surface and below the ice bottom, and a $4.5 \mathrm{~m}$ long rod with thermistors spaced every $10 \mathrm{~cm}$. Using these instruments, the buoys measure a time series of air, ice and ocean temperature, the position of the top and bottom surface of the ice cover, barometric pressure and location. These data allow a determination of ice growth, snow accumulation and melt, top and bottom ice surface ablation, estimates of the ocean heat flux, the net surface heat flux, and the onset of melt and freeze-up. This information provides important insight into the driving forces behind the changes of the ice mass balance.

The major concern regarding the $\mathrm{IMB}$ is that it only provides a point measurement of the ice mass balance. To address this concern and maximize the utility of this tool, it is necessary to explore a critical question: how representative 
are these measurements at larger scales? Can the results be extended to the floe on which the IMB is deployed ( $1 \mathrm{~km})$, the ensemble of floes in the immediate vicinity of the deployment site $(10 \mathrm{~km})$, or the region of study $(100 \mathrm{~km})$ ? In this paper, we use data from the Surface Heat Budget of the Arctic (SHEBA) field experiment to explore the process of extrapolating data collected from the IMB.

\section{OBSERVATIONS}

Ice temperature is a key to determining the ice mass balance. The temperature of the ice cover is primarily governed by air temperatures at the top surface, ocean temperatures and heat fluxes at the bottom surface, and the snow-ice interface temperature. Observations indicate that air temperatures near ( $\sim 2 \mathrm{~m}$ above) the surface of the ice are uniform over large $\left(100 \mathrm{~km}^{2}\right)$ regions, with variations limited to $1-2^{\circ} \mathrm{C}$ (Claffey and others, 1999; Perovich and Elder, 2001). This uniformity is observed to exist all year round. Likewise, ocean temperatures at the underside of the ice are also relatively uniform, with differences less than tenths of a degree. If the ice cover was a slab of uniform thickness, the mass balance of the ice cover would be easy to monitor. Under these circumstances, changes in the air or ocean temperature would cause uniform changes in the mass balance of the ice cover, and a single point measurement of the mass balance would represent the entire ice cover.

In reality, most of the Arctic sea-ice cover exhibits significant spatial variability. It consists of a complex mixture of leads, first-year ice and multi-year ice. Each of these ice types can be further categorized as undeformed, deformed and ponded. Ice thickness ranges from zero, where there is open water, to tens of meters in ridges. The snow cover varies in depth from bare ice to $>1 \mathrm{~m}$ in snowdrifts. These dramatic variations in ice and snow thickness often occur over distances of only tens of meters. For example, a snowdepth and ice-thickness profile, taken on a $500 \mathrm{~m}$ long transect line, shows ice thicknesses ranging from 1 to $>8 \mathrm{~m}$ and snow depth varying from 0 to $0.8 \mathrm{~m}$. While there was some correlation between snow depth and ice topography, reflecting the impact of surface roughness on snowdrift patterns, this correlation is not strong. Regardless of the scale of consideration, the inherent variability of the ice cover significantly impacts the heat budget of the ice cover and hence its mass balance.

Observations on ice mass balance collected during the SHEBA program can be used to understand the link between variations in the snow and ice distribution and the heat budget. SHEBA was a comprehensive investigation of sea-ice thermodynamics, linking scales from meters to kilometers (Perovich and others, 1999). The centerpiece of the study was a year-long drift experiment, which included extensive observations of the temporal and spatial variability of the surface heat budget and ice mass balance. Perovich and others (2003) describe the results of over 100 ice massbalance measurement sites, located to encompass all observed ice types. These sites included first-year ice, ponded ice, unponded ice, multi-year ice, hummocks, new ridges and old ridges. Each site consisted of an ablation stake and a thickness gauge that were manually read. The variability of snow depth and ice thickness at these sites is demonstrated in Figure 1, which is a scattergram of the snow depth and ice thickness for each gauge at the end of the growth season in mid-May 1998. The initial ice thicknesses

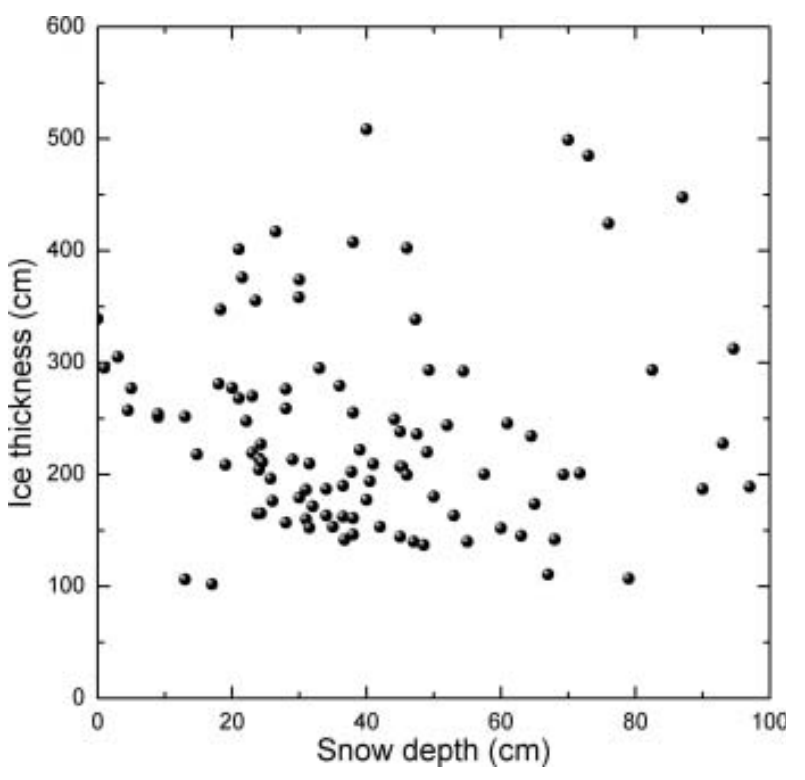

Fig. 1. Variability in snow depth and ice thickness measured at over 100 sites in mid-May.

for these sites ranged from 0.3 to $8 \mathrm{~m}$. Initial snow depths varied from a few centimeters to $>1 \mathrm{~m}$ (Sturm and others, 2002). There was tremendous variability and little correlation between ice thickness and snow depth. For example, $3 \mathrm{~m}$ thick ice had snow depths ranging from 0 to $0.9 \mathrm{~m}$. Similarly, a snow depth of $0.4 \mathrm{~m}$ was found on ice ranging in thickness from 1.5 to $5.5 \mathrm{~m}$. The differences in snow depth and ice thickness contributed significantly to the observed variability in accretion and ablation. The average winter ice growth was $0.51 \mathrm{~m}$. The average summer melt was $1.26 \mathrm{~m}$, consisting of $0.64 \mathrm{~m}$ of surface melt and $0.62 \mathrm{~m}$ of bottom melt. It was clear that both snow depth and ice thickness caused a difference in the mass balance between the sites. However, at every site, independent of ice type, there was a net thinning of the ice during the SHEBA experiment.

\section{Heat budget}

As a prelude to considering the SHEBA results, it is useful to briefly review the components of the heat budget at the top and bottom surface of the ice cover and consider their dependency on the conditions of the ice cover, since these are the factors that govern the ice mass balance. The longwave and turbulent fluxes are not significantly affected by the conditions of the ice cover. While the incident shortwave radiation is uniform, melt albedos during summer vary from approximately 0.65 for bare ice to as little as 0.2 for ponded ice. Consequently, there is considerable variation in the shortwave radiation absorbed in the ice (Perovich and others, 2002). During the growth season the conductive heat flux depends strongly on the snow depth and ice thickness and impacts the growth of the ice cover. The influence of the conductive components is minimal in the summer, when the ice cover is close to isothermal.

At the bottom of the ice cover, the heat budget is a function of the ocean heat flux as well as conduction through the ice cover. Both of these components are affected by conditions of the ice cover. Like the top surface, the conductive component dominates the energy budget in the winter and is significantly influenced by the snow depth and ice thickness. It is diminished in the summer when the ice 


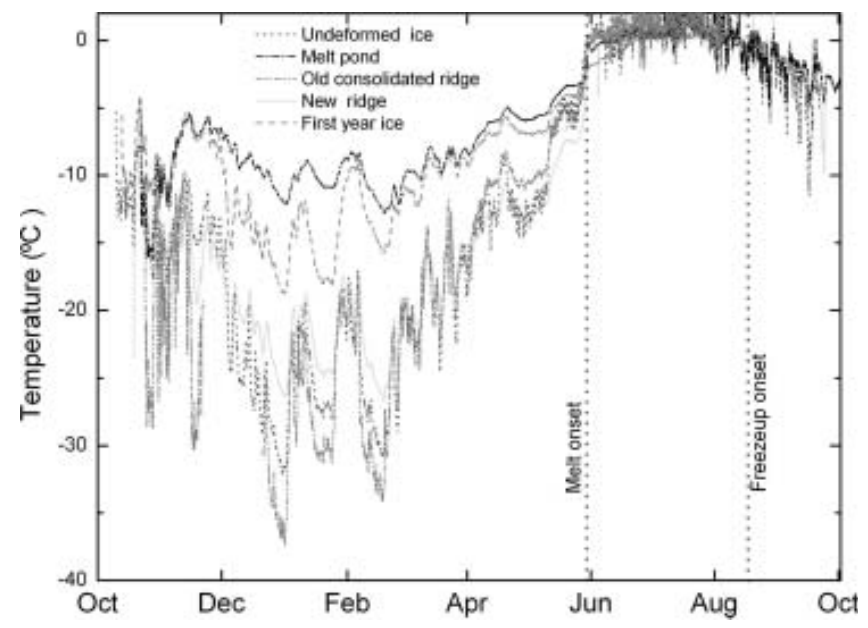

Fig. 2. The annual cycle of snow-ice interface temperatures measured at five locations during the SHEBA field program.

becomes isothermal. Conversely, the ocean heat flux becomes dominant in the summer, when solar input is warming the upper ocean. The ocean heat flux is also strongly influenced by the bottom topography of the ice (Wettlaufer, 1991). It is larger for rough, deformed ice and smaller for smooth flat ice. During SHEBA, Perovich and Elder (2001) showed that the variability in ocean heat flux could be characterized by ice type: $7.5 \mathrm{~W} \mathrm{~m}^{-2}$ for undeformed ice, $10.4 \mathrm{~W} \mathrm{~m}^{-2}$ for ponded ice and $12.4 \mathrm{~W} \mathrm{~m}^{-2}$ for deformed ice. In the summer months, the variation was more pronounced, ranging by a factor of 3 , from $10 \mathrm{~W} \mathrm{~m}^{-2}$ for undeformed ice to $30 \mathrm{~W} \mathrm{~m}^{-2}$ for deformed ice. Large ridge keels were particularly effective at absorbing heat.

The variability of snow and ice temperature is illustrated in Figure 2, which shows the annual cycle of snow-ice interface temperatures measured at five locations during SHEBA. These sites included undeformed multi-year, firstyear ice, ponded ice, an old consolidated ridge and a new ridge. The differences in interface temperature are greatest during the winter, when temperatures are at their coldest. For example, interface temperatures in early January ranged from $-40^{\circ} \mathrm{C}$ at a thick consolidated ridge with shallow snow to $-10^{\circ} \mathrm{C}$ at a thin-ice site with deep snow. In general during the winter, the relatively thin ice types (first-year ice and ponded ice) and ice with deep snow covers (melt ponds) exhibited significantly warmer temperatures than thicker ice with thinner snow (crests of ridges). Soon after the onset of melt, once all of the snow cover has melted away, the difference in interface temperature (now the ice surface temperature) becomes negligible. Variations become apparent, again, once freeze-up begins. Concurrent measurements of snow depth and ice thickness at these sites indicate that the primary cause for variations of the interface temperature, between ice types, is the depth of the snow cover. This is due to the small thermal conductivity of snow. The thicker the snow cover, the higher the interface temperature. The relative thickness of the ice cover also contributes to the variations, but to a lesser extent.

\section{Mass balance}

In its current configuration, the IMB is designed to provide ice mass-balance measurements of multi-year ice in the perennial ice zone (Richter-Menge and others, 2006). For this reason, we focus on results from the SHEBA multi-year sites. Histograms showing the distribution of ice growth, surface melt and bottom melt during SHEBA for multi-year ice are presented in Figure $3 \mathrm{a}, \mathrm{c}$ and e. At first glance, it is apparent that these distributions reflect a system with a significant degree of variability. The ice growth ranges from 0 to $79 \mathrm{~cm}$ (Fig. 3a). Surface melt ranges from 8 to $92 \mathrm{~cm}$ (Fig. 3c). Bottom melt varies from 7 to $115 \mathrm{~cm}$ (Fig. 3e). However, upon closer examination, we can see that each histogram has a well-defined peak, representing approximately one-quarter of all the cases: $60-70 \mathrm{~cm}$ ice growth, $50-60 \mathrm{~cm}$ surface melt and $40-50 \mathrm{~cm}$ bottom melt. Much of the variability in Figure $3 \mathrm{a}, \mathrm{c}$ and e is associated with ridges, deep snow and melt ponds. The variability is reduced considerably by examining only undeformed, unponded multi-year ice. Collectively these ice types represented approximately two-thirds of the ice cover at SHEBA.

Focusing on the undeformed and unponded multi-year ice samples substantially reduces the variance in the mass balance. Figure $3 \mathrm{~b}$ shows that $50 \%$ of the undeformed multiyear sites experienced $50-70 \mathrm{~cm}$ of ice growth. In the case of surface melt, over one-third of the undeformed multi-year ice sites that were unponded had $50-60 \mathrm{~cm}$ of surface melt and $53 \%$ had $40-60 \mathrm{~cm}$. Similarly, the distribution of bottom melt also exhibits a peak, with almost $30 \%$ of the gauges having $40-50 \mathrm{~cm}$ of bottom melt and over $50 \%$ having $35-55 \mathrm{~cm}$.

\section{DISCUSSION}

In general during SHEBA, about $50 \%$ of the observed changes in the mass balance of the ice cover are represented within a $20 \mathrm{~cm}$ range of ice thickness. This was true regardless of whether the change was the result of ice growth or surface or bottom melt. This result implies that a single IMB can be representative of 'typical' local conditions, if the installation site is selected correctly. This requires care in the selection of the deployment site, locating it in undeformed, multi-year ice. The first step is identifying a representative multi-year ice floe. By representative, we mean that the multi-year ice floe selected for a deployment site is of average size, relative to the region of study. This is typically determined from air reconnaissance flights, looking for a relatively uniform expanse of small hummocks, which are typically $<1 \mathrm{~m}$ high and extend over an area of at least tens of meters. If possible, a thickness measurement is also taken using an ice auger. Once a floe is selected, a specific site for the buoy deployment must be determined. The key is to avoid ridges and melt ponds, since the ice thickness at these locations is not representative. Deep snow cover or drifts are also common near ridges and over frozen melt ponds. Avoiding melt ponds facilitates data collection over multiple annual cycles, since unponded ice sites are more likely to survive the summer melt. We have not observed any bias towards preferential melting in the unponded ice. In practice, once on the floe, site selection is straightforward and only takes about $15 \mathrm{~min}$.

The design of a larger-scale network of IMBs also hinges on the deliberate and intelligent selection of deployment sites. In this case, different regions are identified based on thermodynamic and dynamic behavior. For instance, multiyear ice located in the Beaufort Gyre and that located in the Transpolar Drift experience different variations in mass balance. Observations combined with sea-ice models of the Arctic basin can be used to identify regions of contrasted 

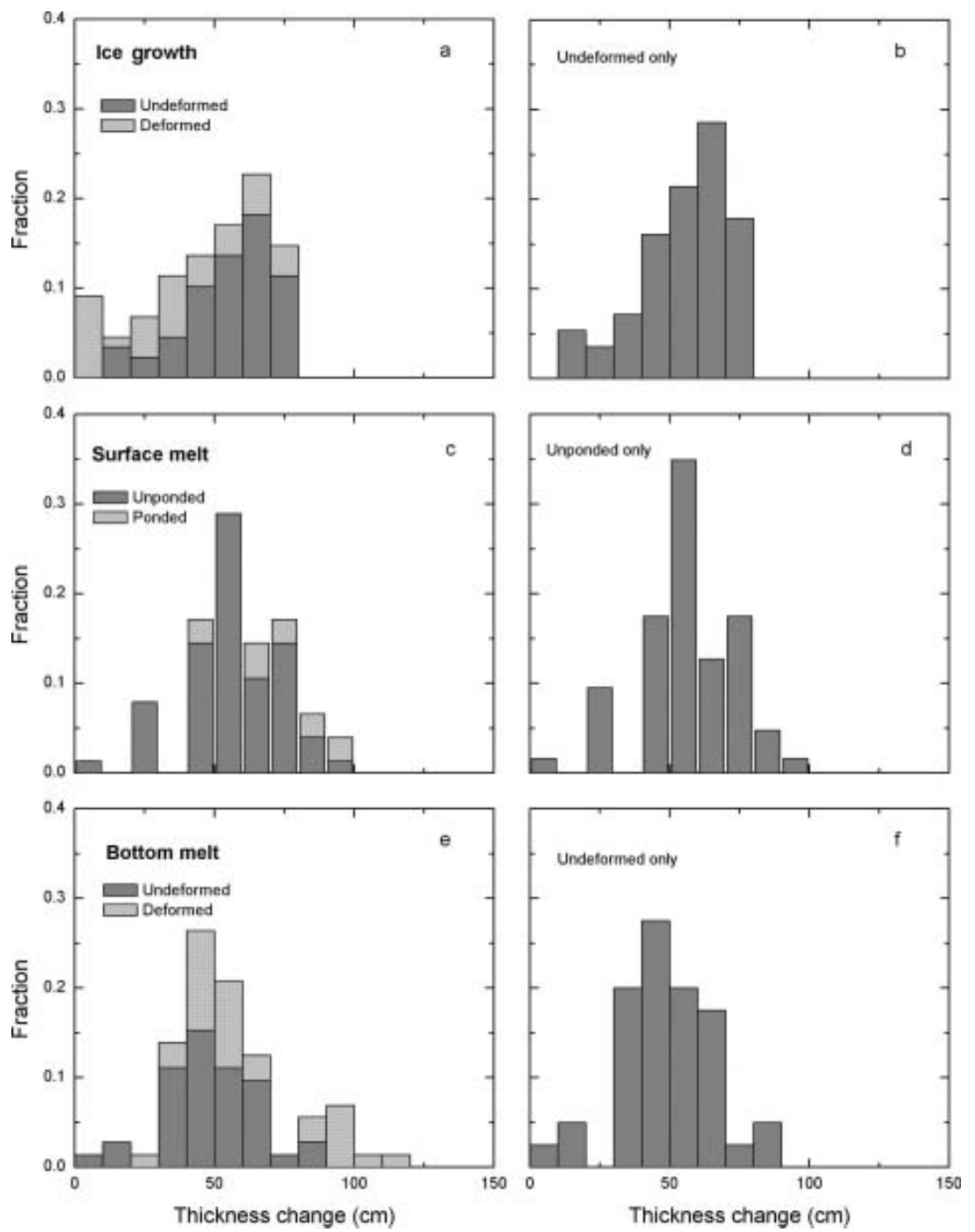

Fig. 3. Mass-balance histograms of ice growth, surface melt and bottom melt tabulated from measurements selected from 100 sites measured during the SHEBA field campaign. (a), (c) and (e) include data from all of the sites. (b), (d) and (f) only include data from sites located on undeformed and unponded ice.

mass balance. A complete network of IMBs would include deployment sites in each region.

The IMB is not a perfect tool, primarily because of its spatial limitations. However, it is the only tool currently available to autonomously measure changes in the mass balance of the ice cover. Other comparable tools are limited to measuring changes in the thickness of the ice cover, but they cannot attribute the cause for the change. These tools include satellite-based altimeters (Laxon and others, 2003; Kwok and others, 2004); submarine and mooring-based iceprofiling sonar (Melling and Riedel, 1996; Rothrock and others, 1999) and helicopter-borne, ship-based or on-ice electromagnetic induction devices (Eicken and others, 2001; Haas, 2004).

Ideally, the strengths of these tools can be combined to effectively monitor the mass balance of the sea-ice cover over large spatial and temporal scales. The central role of the IMB is to provide measurement of the mass balance of the ice over long periods at a high temporal resolution. IMB data provide critical insight into the driving forces governing variations in the state of the snow and ice cover. Common among many of the other tools is the complementary ability to extend the spatial scales. For example, the IMB is a drifting platform, and the mooring-based iceprofiling sonar is a fixed platform, hence combined they provide Eulerian and Lagrangian perspectives. A network of IMBs and moorings can be located in regions where submarine and helicopter-borne electromagnetic surveys are conducted. The IMBs and moorings would provide a temporal link between survey missions. The submarine and helicopter-based surveys would extend the spatial coverage of the IMBs and moorings. Data from all of these instruments can be used to validate and calibrate remotesensing tools, including satellite-based instrumentation design to measure ice thickness or the onset and end of surface melt. Numerical models can be used to assimilate these data, present a context for the data and provide a predictive capability.

\section{CONCLUSIONS AND FUTURE WORK}

Ice mass-balance observations provide important information about changes in the characteristics of the sea-ice cover. More critical, however, is their role in establishing and understanding the source of changes. Ice mass-balance measurements can provide information on whether a change 
was caused by dynamic or thermodynamics processes; whether a change took place under winter or summer conditions; and whether a change was the result of atmospheric or oceanic forcing.

IMBs provide a unique tool for collecting ice massbalance measurements, especially in perennial ice where a deployment can yield multiple years of data. While the technology only provides a point measurement of the ice mass balance, judicious selection of the measurement site can facilitate the extrapolation of the data to represent larger regions. Since undeformed, unponded multi-year ice is the predominant ice type within the perennial zone, a site that reflects this ice type will optimize the impact of the deployment. Other instruments can be added to an IMB. For example, a pressure sensor could be mounted beneath the ice cover to monitor snow and ice mass balance integrated over the entire ice floe (Untersteiner, 1961). Another key to fully exploiting the mass-balance measurements from IMB deployments is to couple them with other tools that measure ice thickness and provide more spatial coverage. Finally, IMB results can be assimilated into process, regional and basin-wide sea-ice models.

\section{ACKNOWLEDGEMENTS}

This work has been supported by the Cryosphere program of NASA, the Arctic program of the US National Science Foundation and the Arctic Research Program of the US National Oceanic and Atmospheric Administration.

\section{REFERENCES}

Belchansky, G.I., D.C. Douglas and N.G. Platonov. 2004. Duration of the Arctic melt season: regional and interannual variability, 1979-2001. J. Climate, 17(1), 67-80.

Claffey, K.J., E.L. Andreas, D.K. Perovich, C.W. Fairall, P.S. Guest and P.O.G. Persson. 1999. Surface temperature measurements at SHEBA. In Fifth Conference on Polar Meteorology and Oceanography, 10-15 January 1999, Dallas, Texas. Proceedings. Boston, MA, American Meteorological Society, 327-331.

Comiso, J.C. 2002. A rapidly declining perennial sea ice cover in the Arctic. Geophys. Res. Lett., 29(20), 1956. (10.1029/ 2002GL015650.)

Eicken, H., W.B. Tucker, III and D.K. Perovich. 2001. Indirect measurements of the mass balance of summer Arctic sea ice with an electromagnetic induction technique. Ann. Glaciol., 33, 194-200.

Haas, C. 2004. Late-summer sea ice thickness variability in the Arctic Transpolar Drift 1991-2001 derived from ground-based electromagnetic sounding. Geophys. Res. Lett., 31(9), L09402. (10.1029/2003GL019394.)

Kwok, R., H.J. Zwally and D. Yi. 2004. ICESat observations of Arctic sea ice: a first look. Geophys. Res. Lett., 31(16), L16401. (10.1029/2004GL020309.)

Laxon, S., N. Peacock and D. Smith. 2003. High interannual variability in sea ice thickness in the Arctic region. Nature, 425(6961), 947-950.

Melling, H. and D.A. Riedel. 1996. Development of seasonal pack ice in the Beaufort Sea during the winter of 1991-1992: a view from below. J. Geophys. Res., 101(C5), 11,975-11,991.

Parkinson, C.L. and D.J. Cavalieri. 2002. A 21 year record of Arctic sea-ice extents and their regional, seasonal and monthly variability and trends. Ann. Glaciol., 34, 441-446.

Parkinson, C.L., D.J. Cavalieri, P. Gloersen, H.J. Zwally and J.C. Comiso. 1999. Arctic sea ice extents, areas, and trends, 1978-1996. J. Geophys. Res., 104(C9), 20,837-20,856.

Perovich, D.K. and B.C. Elder. 2001. Temporal evolution of Arctic sea-ice temperature. Ann. Glaciol., 33, 207-211.

Perovich, D.K. and 22 others. 1999. Year on ice gives climate insights. EOS Trans. AGU, 80(41), 481, 485-486.

Perovich, D.K., T.C. Grenfell, B. Light and P.V. Hobbs. 2002. The seasonal evolution of Arctic sea ice albedo. J. Geophys. Res., 107(C10), 8044. (10.1029/2000JC000438.)

Perovich, D.K., T.C. Grenfell, J.A. Richter-Menge, B. Light, W.B. Tucker, III and H. Eicken. 2003. Thin and thinner: ice mass balance measurements during SHEBA. J. Geophys. Res., 108(C3), 8050. (10.1029/2001JC001079.)

Richter-Menge, J.A., D.K. Perovich, B.C. Elder, K. Claffey, I. Rigor and M. Ortmeyer. 2006. Ice mass-balance buoys: a tool for measuring and attributing changes in the thickness of the Arctic sea-ice cover. Ann. Glaciol., $\mathbf{4 4}$ (see paper in this volume).

Rothrock, D.A., Y. Yu and G.A. Maykut. 1999. Thinning of the Arctic sea-ice cover. Geophys. Res. Lett., 26(23), 3469-3472.

Stroeve, J.C. and 6 others. 2005. Tracking the Arctic's shrinking ice cover: another extreme September minimum in 2004. Geophys. Res. Lett., 32(4), L04501. (10.1029/2004GL021810.)

Sturm, M., J. Holmgren and D.K. Perovich. 2002. Winter snow cover on the sea ice of the Arctic Ocean at the Surface Heat Budget of the Arctic Ocean (SHEBA): temporal evolution and spatial variability. J. Geophys. Res., 107(C10), 8047. (10.1029/ 2000JC000400.)

Tucker, W.B., III, J.W. Weatherly, D.T. Eppler, D. Farmer and D.L. Bentley. 2001. Evidence for rapid thinning of sea ice in the western Arctic Ocean at the end of the 1980s. Geophys. Res. Lett., 28(9), 2851-2854.

Untersteiner, N. 1961. On the mass and heat budget of Arctic sea ice. Arch. Meteorol. Geophys. Bioklimatol., Ser. A., 12(2), 151-182.

Wadhams, P. and N.R. Davis. 2000. Further evidence of sea ice thinning in the Arctic Ocean. Geophys. Res. Lett., 27(24), 3973-3976.

Wettlaufer, J.S. 1991. Heat flux at the ice-ocean interface. J. Geophys. Res., 96(C4), 7215-7236. 